\title{
MÚSICA EN PIEDRA: MÚSICA, MÚSICOS Y CANTANTES EN LOS ÁLBUMES DE FIRMAS DEL MONASTERIO DE PIEDRA ENTRE 1861 Y 1912
}

\author{
MUSIC IN PIEDRA (STONE): MUSIC, MUSICIANS AND SINGERS \\ IN THE MONASTERY OF PIEDRA'S SIGNATURE BOOKS BETWEEN \\ 1861 AND 1912
}

\author{
Pilar Bosqued Lacambra \\ Universidad de Zaragoza
}

\begin{abstract}
Resumen
En 1861 J. Federico Muntadas Jornet comenzó un álbum donde recogió las firmas de los amigos, familiares y personalidades que pasaron por el Monasterio de Piedra, donde falleció en 1912. En este artículo, se dan a conocer algunos autógrafos, fechas e impresiones, de compositores, músicos y cantantes que estuvieron en Piedra entre 1861 y 1912, acompañados por comentarios al respecto.
\end{abstract}

\section{Palabras clave}

Muntadas, Monasterio de Piedra, música, músicos, compositores, cantantes.

\section{BREVE INTRODUCCIÓN}

El monasterio de Piedra, localizado a unos tres kilómetros de Nuévalos, Zaragoza, fue fundado a finales del siglo XII por los monjes cistercienses, quienes después de la desamortización de 1835 se vieron obligados a abandonar definitivamente el lugar.

El cenobio, ubicado en una hondonada, se descubre en las inmediaciones. Las murallas rodean las huertas y los principales edificios a excepción del lugar por el que río Piedra entra al recinto despeñándose por entre escarpadas paredes rocosas. Tras recorrer el vergel, el río sale por un estrecho formando la impresionante cascada conocida

\begin{abstract}
In $1861 \mathrm{~J}$. Federico Muntadas began a signature book in which he collected signatures of friends, family and prominent personalities, that went to the Monastery of Piedra, where he passed away in 1912. In this article, we present some signatures, dates and impressions from some composers, musicians and singers, that were in Piedra between 1861 and 1912 followed by comments.
\end{abstract}

Key words

Muntadas, Monastery of Piedra (Stone), music, musicians, composers, singers.

como Cola de Caballo. Fuera ya de las murallas, a los pies de la mencionada cascada, se localiza el valle de la Hoz, la zona del Lago del Espejo y la piscifactoría, construida junto al río Piedra que prosigue su curso hacia la población nuevalina.

Las cualidades y condiciones artísticas, históricas, literarias, culturales y estéticas en la arquitectura, en el parque, vergel y jardín, y en el paisaje del monasterio de Piedra y sus alrededores son fáciles de apreciar, pero resultan desconocidas muchas de las musicales, algunas de las cuales pretendo desvelar. 


\section{EL MONASTERIO DE PIEDRA, LA FAMILIA MUNTADAS Y SU RELACIÓN CON LA MÚSICA}

El igualadino Pablo Muntadas Campeny, adquirió en subasta pública la mayoría de los edificios del Monasterio de Piedra y otras fincas. Tras su muerte, su hijo Federico heredó las propiedades que su progenitor tenía en Aragón ${ }^{1}$.

J. Federico Muntadas Jornet nació en Barcelona en 1826, donde comenzó los estudios. En su juventud marchó a Madrid y realizó cursos universitarios en la Universidad Central, se licenció en Filosofía y en Jurisprudencia, doctorándose en Letras. En 1863 se casó en Zaragoza con su prima hermana $\mathbf{M}^{\mathrm{a}}$ del Carmen Muntadas Mariñosa ${ }^{2}$.

Federico ejerció como escritor y, durante unos años, también como político. Escribió poesía, teatro, dramas, ensayos, y alcanzó su mayor éxito como novelista con su obra Vida y hechos de Gil Pérez de Marchamalo y con su guía sobre el monasterio de Piedra, la cual iba complementada por algunas de sus leyendas ${ }^{3}$.

Resultaría probable que Federico, en su primera juventud, frecuentara la vida musical barcelonesa y que acudiera a las representaciones teatrales, ya que su padre y sus tíos Juan e Isidro fueron socios del Teatro Liceo de Barcelona y tuvieron varias lunetas ${ }^{4}$.

Federico se trasladó a Madrid, en donde se representaron algunas de sus obras literarias en los teatros de la Corte, como el Teatro del Circo, el Teatro de la Comedia (Instituto), el Teatro del Drama y el Teatro de Variedades. Estas obras iban siempre acompañadas por música, por lo que se relacionó estrechamente en la capital con los músicos y la música. Así, en 1846 mantuvo contacto con Bernabé Carrafa ${ }^{5}$.

Además, Federico se hizo socio del Ateneo y del Liceo artístico y literario de Madrid, según aseveraba Soriano, un templo artístico fundado en 1837 donde «el pintor, el músico y el poeta, esponían ( $s i c$ ) en él sus pensamientos y concepciones en medio de una reunión escogida y numerosa $[\ldots] »{ }^{6}$ Estas sociedades favorecieron las relaciones culturales de Muntadas y el contacto con los escritores, poetas, artistas, músicos y el rico ambiente literario y artístico madrileño de mediados del siglo XIX.

1 Datos publicados, pueden consultarse en: BOSQUED (2013).

2 Tuvieron tres hijos: Pilar, Carlos y Ramón. Vivieron la mayor parte de su vida matrimonial entre la capital aragonesa y el monasterio de Piedra.

3 En ocasiones utilizó el seudónimo de Leandro Jornet. JORNET (1871); MUNTADAS (1866).

4 SOCIEDAD DEL GRAN TEATRO DEL LICEO (1897).

5 Carrafa tenía un almacén de música e instrumentos musicales en la calle del Príncipe, 15, Madrid.

6 SORIANO FUERTES (1855): 363.
En algunas obras de Federico se manifiesta el carácter dramático y romántico de sus personajes literarios. Las acciones y escenas quedan unidas a un paisaje con furiosas avenidas de ríos, profundas simas, valles, montañas, paisajes accidentados y bellísimos. La influencia de las leyendas medievales y nórdicas en el joven Muntadas le aproximan a la corriente europea romántica y una influencia wagneriana parece ya notarse en esa temprana fecha. Ciertos paisajes descritos por Federico se comportan como telones de fondo de sus escenas literarias y parecen inspirados, o viceversa, en lo accidentado del terreno del monasterio de Piedra, en su orografía y en las crecidas y riadas del río.

Desde que los cistercienses fundaron el cenobio a finales del siglo XII, los monjes fueron transformando la naturaleza del lugar, en la que sobresalía el río Piedra que formaba algunas cascadas y caídas de agua. Hicieron las necesarias conducciones de agua, acequias, estanques y derivaciones diversas, de manera que pudieron regar las huertas y tierras de cultivo intramuros y fincas más próximas y un vergel de frutales. También utilizaron las conducciones para aprovecharlas para usos domésticos.

Tras la desamortización de 1835, y sobre todo con los nuevos propietarios, las huertas y el vergel monásticos de Piedra evolucionaron hasta transformarse en un jardín, o parque, romántico, pintoresco y sublime, derivado del estilo paisajista inglés. Se introdujo un recorrido lleno de sorprendentes vistas, emociones y sorpresas a través de rampas, escaleras, miradores, túneles excavados en la roca y senderos desde los que se disfruta del río, de las cascadas, corrientes, arroyos y caídas de agua, de los estanques y lagos, de las grutas y paredes escarpadas y del frescor y frondosidad de la vegetación.

Esto se refleja en el plano de Eugenio Rubio, firmado en Calatayud el 23 de junio de 1846, donde se observa una gruta «de don Federico», que luego recibirá el nombre de Gruta del artista, y varias cascadas sin nombre, a excepción de la de la Cola de Caballo, así como un paseo nuevo junto a la orilla del río que descubría la vista y el disfrute de las cascadas. Conviene resaltar que Federico valoró el potencial sonoro de las cascadas que había en Piedra, la mayoría formadas por el hombre.

Al parecer, ciertas escenas jardineras y paisajistas que se compusieron hacia mediados del siglo XIX se ejecutaron según principios estéticos y artísticos ${ }^{7}$, y existen indicios de que algunas de las actuaciones podrían haber estado encaminadas a la disposición teatral y escénica en el lugar para la

7 BOSQUED, Pilar: El parque, vergel y jardín del Monasterio de Piedra. (Texto inédito). 
posible representación de obras, música o espectáculos diversos, con el aprovechamiento y disposición necesaria del terreno para ello.

Por su parte, los edificios monacales, algunos de ellos en ruinas, los montes y escarpados acantilados, el paisaje, la especial disposición del monasterio en tan accidentada orografía, proporcionaban los elementos decorativos complementarios y el ambiente y decorados perfectos.

Esto mismo observaba Víctor Balaguer, quien mencionaba al respecto en su guía sobre el lugar que «Piedra tiene algo de teatro» y que si «se cierran los ojos, se oye el rechinar de una puerta, como si dijéramos el crujido de un telon que se rasga, y al abrir los ojos de nuevo ve uno desplegarse á su vista, como por mágia, una maravillosa decoración llena de luz, de arte, de encantos, de color, de vida y de armonía $»^{8}$.

La singular naturaleza y escenario jardinero, cuyas principales actuaciones realizadas en el siglo XIX podrían darse por finalizadas hacia 1871, ha sido declarado como el primer Jardín Histórico de la Comunidad de Aragón ${ }^{9}$. Los edificios monacales se reformaron y restauraron convirtiéndolos en hospedería, fonda, hotel, bar-restaurante y viviendas particulares. El monasterio de Piedra está declarado Monumento ${ }^{10}$.

Las distintas actividades que Federico Muntadas y otros realizaron, o mandaron realizar, en la propiedad sirvieron para enriquecerla y para atraer a los turistas y viajeros hacia Piedra. Dieron publicidad a su residencia y desarrollaron de forma pionera el turismo y la piscicultura, explotando durante algunos años de manera privada el establecimiento de piscicultura ${ }^{11} \mathrm{y}$ una fuente de aguas mineromedicinales ${ }^{12}$.

Como acabamos de decir, sería posible que ciertos proyectos para atraer turistas hasta el apartado monasterio de Piedra tuvieran relación con el teatro y la música. No en vano, Piedra distaba en la época a unas dos horas de Alhama de Aragón, en aquel momento uno de los balnearios más concurridos de la península, desde donde salían «dos expediciones diarias para Piedra desde Mayo á Octubre» ${ }^{13}$ y donde estaba la estación de tren más cercana de la línea MadridZaragoza-Barcelona.

8 BALAGUER (1882): 54.

9 Boletín Oficial de Aragón, 22 septiembre 2010.

10 Boletín Oficial de Aragón, 7 octubre 2009.

11 BOSQUED, Pilar: J. Federico Muntadas y la Piscifactoría del Monasterio de Piedra. Breve historia (Conferencia inédita, Facultad de Veterinaria, Universidad de Zaragoza, 6 de mayo de 2010); BOSQUED (2013): 65-80. BOSQUED, Pilar: Historia de la piscifactoría del Monasterio de Piedra (inédito).

12 BOSQUED (2013); BOSQUED (2010).

13 BALAGUER (1882): «Noticias útiles á los viajeros.»
Así lo aseguraba Muntadas al publicar en su guía que «por centenares se cuentan los curiosos que desde los baños de Alhama de Aragón van á visitar todos los años las maravillas que encierra el monasterio de Piedra, situado á 17 kilómetros de aquel pueblo, y en los dos últimos, muchas personas han acudido directamente de algunas capitales, sobre todo de Madrid, Zaragoza y Barcelona ${ }^{14}$.

Fueron varios los intentos de los Muntadas por mejorar las comunicaciones hasta el monasterio de Piedra, conscientes de la dificultad para llegar hasta allí. De este modo utilizaron sus contactos e influencias en varias ocasiones para intentar llevar un ramal de tren desde Alhama de Aragón y para construir y mejorar la carretera y accesos.

Lo cierto es que los huéspedes y viajeros llegaban a Piedra, y para entretenerlos y divertirlos en sus momentos de ocio después de comer, cenar o visitar el parque, vergel, jardín y el monumento, hubo un piano a su disposición en los salones del monasterio, donde se celebraban veladas musicales.

En 1890 se publicó ${ }^{15}$ una partitura musical de una balada con una poesía de Federico titulada Recuerdo del Monasterio de Piedra ;Sin él!, con música del eminente maestro Manuel Fernández Caballero. Estaba dedicada a su mujer, A la Sra. $D^{a}$ Carmen Muntadas de Muntadas, y la letra rememoraba el bosque umbrío, los lagos, las verdes enramadas, las cascadas, las grutas, la floresta, el vergel, las flores, el río y las peñas, es decir, muchos de los elementos de su propiedad en el parque, vergel y jardín del monasterio de Piedra. Sería bien probable que esta balada se hubiera tocado en Piedra.

$\mathrm{Al}$ parecer, se idearon para Piedra varios proyectos relacionados con la música y el lugar, los cuales se repitieron en el primer decenio del siglo XX, poco antes de que falleciera Federico Muntadas, cuando las asociaciones wagnerianas de Madrid y Barcelona pensaron que el monasterio de Piedra era un enclave idóneo para representar algunas de las obras de Wagner.

En cualquier caso, en la segunda mitad del siglo XIX y especialmente mientras que Federico residió en el monasterio de Piedra, el lugar estuvo muy concurrido. Allí acudieron y encontraron inspiración muchos de los artistas de la época, tanto pintores ${ }^{16}$ como escritores, fotógrafos y músicos, muy célebres algunos de ellos, entre los que se encontraban también políticos así como otras personalidades de la sociedad civil y del ámbito eclesiástico o militar.

14 JORNET [MUNTADAS] [1871]: III.

15 Ilustración musical hispano-americana. Barcelona, 15 y 30 de julio de 1890 .

16 BOSQUED (2012-2013): 119-139. 
Algunas de esas visitas quedaron anotadas en los álbumes de firmas que la familia Muntadas conserva y custodia celosamente ${ }^{17}$.

En el año 1882 Víctor Balaguer publicó una Guía del viajero en Piedra donde reseñó en el capítulo «El álbum de Piedra» la presencia de dos músicos: Barbieri y Arrieta $^{18}$. Del mismo modo, Rafael Heredia editó en 1900 un Álbum del Monasterio de Piedra con vistas fotográficas y autógrafos seleccionados entre los que incluyó a Arrieta, Sarasate, Gayarre, Barbieri, Vázquez y Chapí19. Por su parte, los primos Elvira Muntadas Nagel y Luis Muntadas-Prim Salvadó dieron a conocer en 1970 algunas de las firmas que identificaron en los álbumes, actualizando las firmas hasta 1969 e incluyendo las de Arrieta, Sarasate, Gayarre, Barbieri y Chapí ${ }^{20}$. Años más tarde, en 1994, Jesús Andrés Zueco realizó el estudio, compilación y notas al De Piedra a Piedra de Joaquín Dicenta Benedicto, donde reprodujo firmas, comentarios e impresiones reflejados en los álbumes de Barbieri, Arrieta, Chapí, Sarasate y Gayarre ${ }^{21}$.

A continuación, y siguiendo el orden cronológico en los álbumes, reproduzco las 20 personas, o instituciones, seleccionadas relacionadas con el tema que aquí se aborda, y que son Teodora Lamadrid, Barbieri, Harztenbusch, Hilario Prádanos, Ignacio Bauer, Miguel Ramos Carrión, Arrieta, Víctor Balaguer, Pablo Sarasate, Manuel Pérez Badía, Otto Goldschmidt, Julián Gayarre, Evaristo Arnús, Carlos Fernández Shaw, Mariano Vázquez, Gompertz y Vinck, Ruperto Chapí, Vicente Zurrón, José López Salaberry, así como la Asociación wagneriana de Barcelona.

El texto se complementa con aclaraciones respecto a la relación de quienes firmaron con los propietarios, familiares y amigos, y con el recinto del Monasterio de Piedra, el parque, vergel y jardín, y el paisaje contiguo.

La mayoría de los datos musicales y biográficos que se citan proceden de los diccionarios de música de Casares $^{22}$.

17 Con motivo de mi tesis doctoral tuve acceso a los álbumes de firmas. En el presente artículo se analizan dos de ellos: el primero, que comienza el 5 de abril de 1861 y termina el 6 de agosto de 1891 , y del segundo se estudia en este artículo hasta 1912, año en que falleció Federico Muntadas.

18 BALAGUER (1882): 137-157.

19 HEREDIA (1900).

20 MUNTADAS NAGEL; MUNTADAS-PRIM SALVADÓ (1970)

21 DICENTA (1994).

22 CASARES RODICIO (1999-2002); CASARES RODICIO

(2006). No se volverá a citar. Consúltense para mayor información.

\section{MÚSICA, MÚSICOS, COMPOSITORES Y CANTANTES EN LOS ÁLBUMES DE FIRMAS DEL MONASTERIO DE PIEDRA (1861-1912)}

Después del nombre, las fechas anotadas en los álbumes y comentarios al respecto.

\subsection{Teodora Lamadrid, 19 de septiembre de 1867}

La actriz aragonesa Teodora Hervella Cano, conocida por su nombre artístico de Teodora Lamadrid, destacó en teatro, especialmente en el drama, aunque también hizo comedia. Completó su faceta artística actuando como cantante de ópera y zarzuela. Quiso dejar testimonio de su amistad y agradecimiento a Federico escribiendo:

Setiembre 19 de 1867.

Su agradecida y Leal amiga

Teodora Lamadrid [firma]. (Fig. 1)

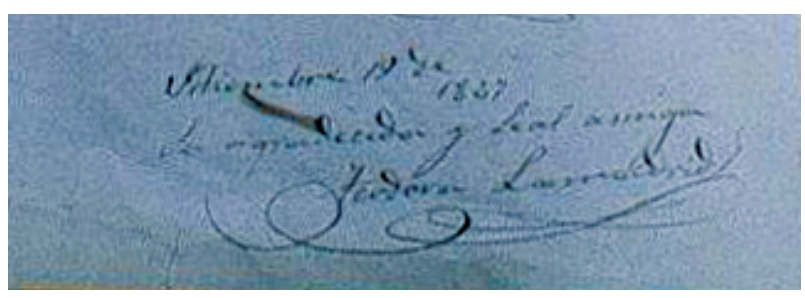

Figura 1. Autógrafo de Teodora Lamadrid en el álbum de firmas. Imagen cortesía propiedad. Fot. autora.

Teodora fue acompañada de su hija, también cantante, Enriqueta Basili Lamadrid, la cual firmó a continuación de su madre sin añadir nada. Como se sabe, Teodora se casó con su profesor de canto, el italiano Basili, compositor, cantante y director.

La estrecha relación entre Federico y Teodora se reflejó en el drama heroico en tres actos y en verso escrito por Federico a beneficio de la artista, drama titulado Boadicea, donde la actriz interpretó el papel de Boadicea, la reina de los icenos, el cual se estrenó en Madrid en 1853 en el teatro Variedades ${ }^{23}$, el miércoles 16 de febrero a las ocho de la noche precedida de la Sinfonía de Carlos VI. Después, se tocó la Sinfonía de la Novena (o Norma) y se representó la comedia en un acto titulada Los guantes amarillos ${ }^{24}$.

Esta relación continuó años más tarde, cuando Federico volvió a escribir para Teodora el drama en tres actos y en

23 MUNTADAS [1853]: 1-3.

24 Gaceta de Madrid (en adelante, GM), n 47, 16 febrero 1853. 
prosa, estrenado en Madrid en 1856 en el Teatro del Circo, titulado Deudas pagadas, donde la artista representó el papel de la Marquesa de Valderano.

\subsection{Francisco Asenjo Barbieri, 15 de julio de 1870}

El afamado, exitoso músico y compositor, crítico y director madrileño Francisco Asenjo Barbieri, escribió con manifiesta humildad que: (Fig. 2)

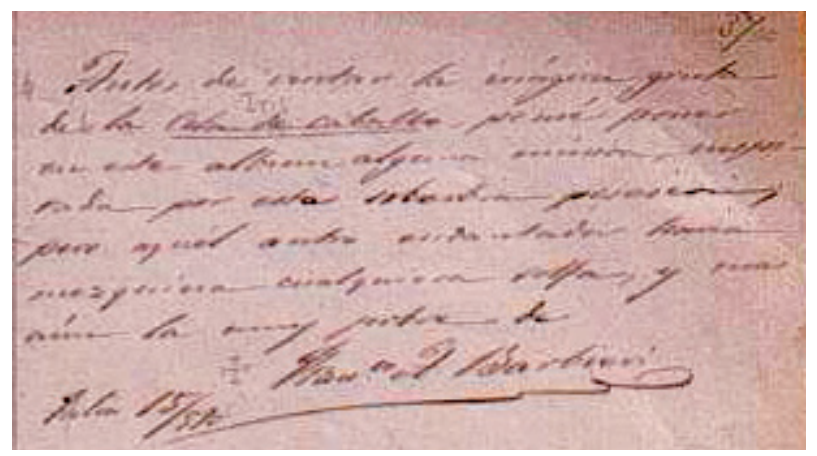

Figura 2. Firma de Francisco A. Barbieri en el álbum. Imagen cortesía propiedad. Fot. autora.

Antes de visitar la mágica gruta de la Cola de Caballo ${ }^{25}$, pensé poner en este album alguna música, inspirada por esta soberbia posesión; pero aquél antro encantador haría mezquina cualquier solfa, $\mathrm{y}$ mas aún la muy pobre de Franc $^{\circ}$ A. Barbieri [firma] Julio $15 / 870$

Lo cierto es que, tal y como observará Chapí en este mismo álbum en 1898 y como veremos más adelante, Barbieri no añadió nota musical alguna. Se refirió a la cascada Cola de Caballo y su impresionante gruta, descubierta en 1861 por Federico Muntadas. Está bautizada como Gruta Iris, puesto que los rayos del sol poniente atraviesan las gotas suspendidas en el aire formando un incomparable espectáculo de arco iris en el interior de la gruta, teniendo como telón de fondo la caída del agua de la cascada. Admitió que el lugar le inspiraba música, pero que la magnitud y belleza de la gruta le había hecho sentirse incapaz de componer.

Tres años después de su visita a Piedra, y desde 1873, Barbieri fue nombrado Académico de número para la sec-

25 Subrayado en el original. ción de Música de la Real Academia de Bellas Artes de San Fernando ${ }^{26}$.

\subsection{Juan Eugenio Hartzenbusch, [julio] de 1871; 16 de agosto de 1872}

Juan Eugenio, amigo personal de Federico Muntadas, dejó en el verano de 1871 sólo la firma, sin anotar la fecha, pero entre otras datadas en julio de 1871 .

En el verano del año siguiente escribió una poesía titulada y dedicada a la mujer de Federico: Al Río Piedra en el ex-monasterio de este nombre.- A Carmen, terminando de la siguiente

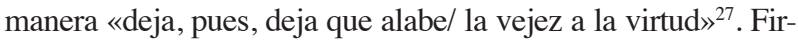
mó las dos veces como Juan Eugenio Hartzenbusch.

Tres años después, en 1875, y por motivos de salud, Hartzenbusch tuvo que dejar su cargo como Director de la Biblioteca Nacional, falleciendo en 1880 . Fue miembro de la Real Academia Española, en la que tomó posesión en 1847 con el discurso sobre el Carácter con que se distinguen las obras de D. Juan Ruiz de Alarcón y Mendoza ${ }^{28}$. Hartzenbusch, destacada figura del drama romántico y autor, entre otras obras, de Los amantes de Teruel, escribió algunas zarzuelas, como El Amor enamorado ${ }^{29}$, a la que el compositor Arrieta puso música.

\subsection{Hilario Prádanos, 4 de septiembre de 1875}

Prádanos fue maestro de Capilla del Pilar de Zaragoza, donde llegó en 1859 y permaneció hasta 1885 , ciudad en la que escribió «la mayor parte de su producción» ${ }^{30}$. Fue elegido académico correspondiente en Zaragoza de la Real Academia de Bellas Artes de San Fernando en $1879^{31}$.

Prádanos escribió en el álbum:

26 realacademiabellasartessanfernando.com/assets/docs/academicos/relacion_general_de_academicos.pdf [última consulta, marzo 2016].

27 BOSQUED, Pilar: Literatura en Piedra: escritores y poesía en los álbumes de firmas del Monasterio de Piedra entre 1861 y 1912. (Texto inédito).

28 http://www.rae.es/academicos/juan-eugenio-hartzenbusch [última consulta marzo 2106].

29 http://www.rae.es/sites/default/files/Discurso_ingreso_Juan_ Eugenio_Hartzenbusch.pdf [última consulta marzo 2106].

http://bdh-rd.bne.es/viewer.vm?id=0000189996\&page=1 [última consulta marzo 2016]: Capricho mitológico, zarzuela burlesca en tres actos, en verso y prosa, de don Juan Eugenio Hartzembusch (sic). 30 CAVIA NAYA (1999): 199-214.

ver:http://www.academia.edu/11684609/Un_m\%C3\%BAsico_ del_siglo_XIX_y_su_proyecci\%C3\%B3n_desde_la_Catedral_de_Valladolid_Hilario_Pr\%C3\%A1danos [última consulta, febrero 2016].

31 realacademiabellasartessanfernando.com/assets/docs/academicos/relacion_general_de_academicos.pdf [última consulta, marzo 2016]. 
Que tube (sic) vocacion, no es un misterio para vestir el trage (sic) de Bernardo; dejare si te place el Magisterio,

Federico, y te doy el gran petardo profesando en tu hermoso Monasterio.

Hilario Prádanos [firma]

4 de Setiembre 1875

Mantuvo relación amistosa con la familia Muntadas. Esto queda reflejado en la carta que María del Carmen y Federico escribieron el 3 de octubre de 1881 a su amigo Víctor Balaguer solicitando una recomendación para Prádanos, «maestro de capilla del Pilar y uno de los beneficiados más antiguo de aquella Metropolitana», para que «le dieran una canongía (sic) en cualquier catedral» ${ }^{32}$.

El matrimonio Muntadas tenía «un verdadero deseo de complacerle [a Prádanos]» y Federico aseguraba que llevaba tres años intentándolo sin conseguir nada, pero pensaba que si Balaguer actuaba «resultaría .... $\underline{\operatorname{algo}}^{33}$, sinonimo de canongía $($ sic $) »^{34}$.

Al parecer, en esta fecha de septiembre de 1875, Hilario Prádanos viajó y/o estuvo en compañía del arzobispo de Zaragoza, Manuel García Gil ${ }^{35}$, el cual escribió unas líneas en la misma fecha y firmó como «Fr. Manuel Arzobispo de Zaragoza».

\subsection{Ignacio Bauer, 24 de junio de 1877}

Ignacio Bauer Landauer, natural de Budapest, banquero y socio de la agencia Rothschild de Madrid ${ }^{36}$, cuyo palacio madrileño es actualmente la Escuela Superior de Canto de Madrid $^{37}$, tuvo una destacada vida musical. Organizó junto a su mujer actividades musicales en su domicilio, actuando como mecenas de artistas, entre otros de los músicos y representaciones musicales.

Al parecer, Bauer acudió a Piedra en 1877 en compañía de su mujer, Ida Morpurgo Parente, quien firmó junto a su marido como Ida Bauer ${ }^{38}$. Acompañaba a sus firmas la fecha reseñada.

32 BIBLIOTECA-ARXIU VÍCTOR BALAGUER (en adelante, BVB).

33 Subrayado en el original.

34 BVB.

35 También firmó en el álbum en el año 1879.

36 Ver al respecto: LÓPEZ MORELL (2005).

37 En la madrileña calle de San Bernardo, número 44, esquina a la calle del Pez, antes denominada Calle Ancha de San Bernardo número 54. Ver para mayor información: http://www.escm.es/ [última consulta, marzo 2016]

38 Ignacio e Ida tuvieron cuatro hijos: Gustavo, Manuel, Fernando y Paulina.
Conviene destacar que el 18 de junio de 1863 Daniel Weisweiller, representante de la casa de Rothschild, había firmado también en el álbum, donde escribió que lo hacía «Encantado y agradecido». Weisweiller, quien sería nombrado Barón de Weisweiller en 1872 y cuyas fiestas y recepciones fueron igualmente famosas, formó en 1855 con Ignacio Bauer la sociedad Weisweiller \& Bauer Cia. ${ }^{39}$.

Ignacio falleció el 30 de mayo de 1895 sin haber otorgado disposición testamentaria. Las actividades musicales y artísticas, muy frecuentadas y reconocidísimas en la época, fueron continuadas por sus descendientes. Con posterioridad a su muerte, el hijo del matrimonio Bauer, el también banquero Gustavo Bauer Morpurgo, quien nació en 1867 en dicho Palacio de Bauer, prestó a Federico Muntadas cierta cantidad de dinero en efectivo ${ }^{40}$.

A finales del año 1894 Ignacio Bauer había constituido con su hijo Gustavo una sociedad mercantil llamada Ignacio Bauer e hijo, que iba a durar 4 años, aunque apenas duró unos meses, pues fue liquidada tras la muerte de Ignacio Bauer. Los socios, padre e hijo, fueron los representantes en España de los señores Rothschild y la sociedad mencionada establecida se iba a dedicar a los negocios de banca y giro.

El 7 de junio de 1912, y antes de que falleciera Federico Muntadas, Gustavo Bauer fue nombrado, junto a otros individuos, Vocal del Patronato del Museo Nacional de Pintura y de Escultura, luego Museo del Prado ${ }^{41}$.

\subsection{Miguel Ramos Carrión, 24 de junio de 1880}

El destacado libretista zamorano realizó su carrera en Madrid y escribió todos los géneros, sobresaliendo en la creación teatral y como flamante escritor festivo. Fue colaborador de Chapí, y protegido de Hartzenbusch. Arrieta compuso la música de alguna de sus obras.

Escribió igualmente libretos para Fernández Caballero, quien como hemos visto se había relacionado también con Federico Muntadas al escribir la música para una de sus poesías.

Miguel Ramos Carrión escribió en el álbum:

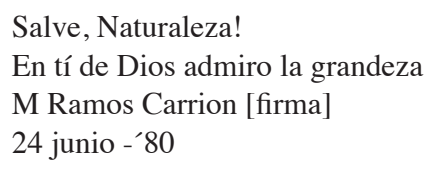

39 Ver n. 36

40 "Certificación relativa a la propiedad [...]". Préstamo de 32.000 pesetas.

41 GM 9 de junio de 1912. 


\subsection{Emilio Arrieta, 7 de agosto de 1880}

El compositor navarro Pascual Juan Emilio Arrieta Corera, quien destacó por las composiciones de zarzuelas, valoró el lugar como perfecto para la creación musical. Escribió en el álbum una profunda reflexión sobre la música y lo que le inspiraba el sitio, estableciendo paralelismo con la música de Beethoven y escogiendo un fragmento de la Sinfonía Pastoral, nombre que «sugiere un tema campestre combinado habitualmente con un elemento mitológico» ${ }^{42}$, y que pertenece, como bien se sabe, a la Sinfonía n 6 en fa mayor, Opus 68 Pastoral:

Dicen que donde acaba la Poesía empieza

la Música; y yo digo, que donde terminan las impresiones de los prodigios de la Naturaleza esparcidos por el mundo comienzan los encantos de Piedra.

Beethoven debió tener en su mente poderosa las grutas, lagos y cascadas que embargan nuestros sentidos, cuando creó su inmortal poema que se llama "Sinfonía Pastoral".

[añadió un pentagrama y un asterisco] *

Agosto 7/1880

Emilio Arrieta [firma]

(*) Fragmento de la Sinfonía pastoral. (Fig. 3)

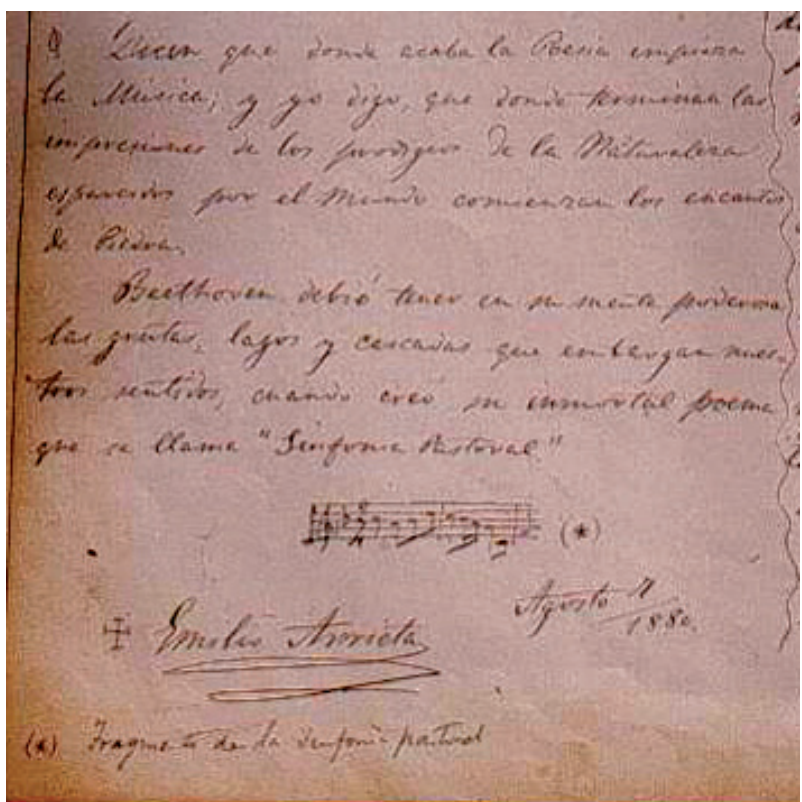

Figura 3. Página del álbum de firmas con el testimonio de Emilio Arrieta. Imagen cortesía propiedad. Fot. autora.

42 SCHOLES (1984): 999.
Arrieta destacó las grutas, lagos y cascadas del monasterio de Piedra, que debieron embargar sus sentidos, y supo valorar el potencial jardinero y paisajista. Resaltó la estrecha convivencia de la literatura y la música y fue el primero en testimoniar que el monasterio de Piedra podría perfectamente haber inspirado a un músico como Beethoven. Arrieta era académico de número para la sección de Música de la Academia de Bellas Artes de San Fernando desde 1873.

\subsection{Víctor Balaguer, 7 y 8 de septiembre de $\mathbf{1 8 8 0}$.}

Víctor Balaguer Cirera, quien estuvo relacionado con la música y fue uno de los iniciadores de los Juegos florales $^{43}$, compuso textos operísticos para Felipe Pedrell y el texto de Melusina de Joan Sariols.

Amigo de Federico y de otros miembros de la familia Muntadas, mantuvo estrecha relación con todos ellos. En agosto de 1880 viajó a Piedra. Escribió en el álbum el 7 de septiembre en catalán y al día siguiente en español. El primer día hizo referencia a la familia Muntadas, firmando ante la cascada Solitaria como Lo trovador de Monserrat:

De Pedra j’ous diré las maravellas [...siguen 19 líneas]

Por su parte, al día siguiente, y a continuación de lo anteriormente escrito, volvió a escribir dedicando algunas líneas en exclusiva a Federico:

\section{A Federico Muntadas,} al partir del monasterio de Piedra ¿Es cierto, pues, que he visto yo cascadas saltar bullentes, con horror y estruendo, junto a lagos azules y adormecidos, siempre en silencio y de reposo eterno? ¿Y es cierto ¿no soñé, que entre peñascos estériles, abruptos y desiertos, cármenes vi y asombrosas alamedas y verdes prados de delicias llenos? ¿Y es cierto, dí, que si una dantesca gruta que descubriste tú, bajé despierto? Ignoro si he soñado lo que he visto ...(1) si no soñé, la realidad es sueño. Monasterio de Piedra 8 setiembre $1880^{44}$ Vict. Balaguer [firma]

(1) Reminiscencia de Cabestany. Je prends mon bien ou je le trouve $e^{45}$.

43 BOSQUED: (v. nota 27).

44 Subrayado en el original.

45 Subrayado en el original. La cita a Cavestany debe referirse a lo que éste dejó escrito el 23 de junio de 1880: “[...] al abandonar esta 
Dos años después de su visita del año 1880, Balaguer publicó un libro sobre el monasterio de Piedra, en el que decía, entre otras muchas cosas, que había estado en septiembre de 1880, fecha en la que comenzó el libro es esas «deliciosas soledades de la residencia de Piedra» y a donde regresó para terminarlo en septiembre de $1881^{46}$. Federico y su mujer habían rogado encarecidamente a Balaguer que fuera a Piedra, sobre todo después del fallecimiento en junio de 1881 de su mujer, Manuela Carbonell ${ }^{47}$. Accedió a ello Balaguer, sin duda buscando el calor de su amigo Federico y de su familia.

Víctor Balaguer fue miembro de la Real Academia Española, donde tomó posesión en $1883^{48}$.

\subsection{Pablo Sarasate, 14 de septiembre de 1882}

El compositor pamplonica Martín Melitón Pablo Sarasate destacó mundialmente por su violín. Cuando visitó Piedra en el verano de 1882 dejó unas líneas escritas, acompañadas por unas notas en un pentagrama:

Vivan las maravillas de España y la amabilidad de Dn Federico Muntadas

Monasterio de Piedra 14 setiembre 82

[pentagrama]

Pablo Sarasate [firma] (Fig. 4)

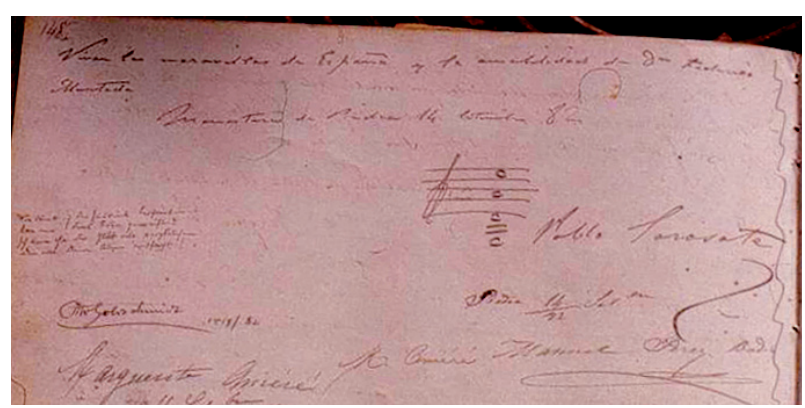

Figura 4. Las impresiones de Pablo Sarasate y acompañantes en el álbum de firmas. Imagen cortesía propiedad. Fot. autora.
Pablo Sarasate debió ir acompañado de Manuel Pérez Badía y Otto Goldschmidt, quienes firmaron en la misma página y en el mismo día.

\subsection{Manuel Pérez Badia, 14 de septiembre de 1882}

El maestro Manuel Pérez Badía firmó a continuación, debajo de Sarasate, sin añadir nada a su firma, excepto la fecha y el lugar. La presencia en el mismo día y la firma de uno a continuación del otro hace pensar que acudieron juntos.

\subsection{Otto Goldschmidt, 14 de septiembre de 1882}

Esto mismo sucede con el pianista, secretario, agente y administrador de Sarasate, Otto Goldschmidt ${ }^{49}$, quien al parecer viajó acompañando a Sarasate, añadiendo unas líneas en alemán, su idioma, seguido de la firma y fecha.

Según manifestaba Arrieta en el prólogo de la obra de Vázquez, Otto Goldschmidt era para Sarasate «su fiel acompañante, alemán de nacimiento y español de corazón $»^{50}$.

\subsection{Julián Gayarre, [¿enero?] de 1887}

En el invierno de 1887, justo después de comenzar el año 1887 en el álbum, el famoso tenor navarro Julián Gayarre Garjón estuvo en Piedra, dejando el testimonio escrito de su paso, tanto escribiendo como cantando. En el álbum de firmas trazó un pentagrama y puso su firma debajo del año.

Luego, alguien, probablemente Federico Muntadas, anotó un texto complementario y un pequeño pentagrama:

El grande artista, después de haber escrito el renglón que antecede, lo bajó al piano. 26 de Enero [pequeño pentagrama] (Fig. 5)

\footnotetext{
hermosura parece qe he soñado lo que he visto![...]".

46 BALAGUER (1885): 3-6. Se lamentaba de la muerte de su mujer.

47 BVB.

$48 \mathrm{http}: / /$ www.rae.es/academicos/victor-balaguer [última consulta marzo 2016].
}

49 http://www.pamplona.es/pablosarasate/index-es.html [última consulta, marzo 2016].

50 VÁZQUEZ (1884): VIII. 


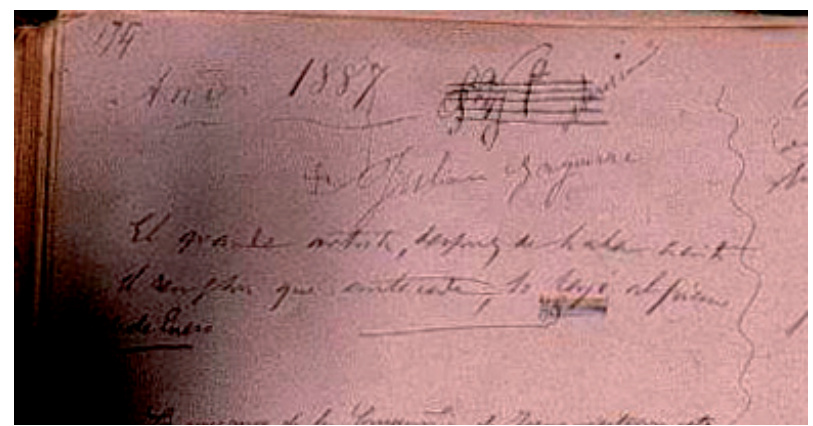

Figura 5. Julián Gayarre en el álbum de firmas del Monasterio de Piedra. Imagen cortesía propiedad. Fot. autora.

Como ya hemos dicho, en los salones del monasterio de Piedra había un piano que amenizaba las tertulias y conversaciones de los turistas, familiares y amigos que se alojaban allí, por lo que se deduce que Gayarre tocó lo que dejó anotado en el álbum.

También dejó el testimonio de su portentosa voz en la naturaleza del lugar, ya que cantó al pie de la Cruz del Monasterio que se localiza frente a la puerta de acceso principal al Monasterio, llamada Puerta del Homenaje.

Según escribió Joaquín Dicenta posteriormente, estando Gayarre sentado al atardecer en uno de los bancos que rodean la cruz:

De repente se puso en pie, avanzó algunos pasos, subió al último escalón, apoyó su mano en la áspera base del granito, levantó hacia el espacio el rostro y preludió el Spirto gentil... Las notas iban saliendo de su garganta como siempre, es decir, con inimitable vibración artística ${ }^{51}$.

Se trata del aria de tenor del acto IV de La Favorita, ópera de Gaetano Donizetti, donde el personaje Fernando rememora su apasionado amor hacia Leonora, la favorita, vencido por la decisión firme de regresar a la vida monástica. Como se aprecia, se trata de un tema en consonancia con el lugar.

Añadió Dicenta que, allí, en tan espectacular escenario y escena: «parecía Gayarre algo más que un hombre, un espíritu sobrehumano que daba cita á toda una época difunta $[\ldots] \gg^{52}$.

Carlos Sarthou-Carreres, quien escribió mucho acerca del monasterio de Piedra, recogió igualmente el suceso y publicó en 1922 el motivo de la denominación de la cruz como tal, escribiendo que

51 El Liberal, 21 abril 1902. Ver igualmente DICENTA (1994). 52 El Liberal, 21 abril 1902. Y DICENTA (1994). al son de la música incesante de la catarata el inmortal Gayarre dedicó a este secular cenobio las mejores notas de su privilegiada voz, a la luz de la luna, sentado en los peldaños de la cruz terminal. Y el rumor de veinte cascadas, con el eco de los precipicios parece que haga perdurar eternamente las postreras notas de un grandioso himno al monasterio de Piedra ${ }^{53}$.

El paisaje potenció la actuación musical de Gayarre, quien conmovido por el espectacular y sublime panorama y por la hora del atardecer no pudo reprimir su espíritu artístico y cantó, en definitiva, al arte, a la historia y a la naturaleza.

La improvisada sesión debió ser memorable y por ello, por memorizar, la propiedad, recordando sin duda tal día, bautizó el lugar y el mirador próximo como Mirador de Gayarre y a la cruz de hierro sobre piedra también se le conoce como Cruz de Gayarre. Desde allí se observa una preciosa panorámica que abarca el valle de la $\mathrm{Hoz}$, la Peña del Diablo, la Lastra, la Puerta del Homenaje, las murallas del monasterio y los montes que lo rodean. (Fig. 6).

El mausoleo de Gayarre fue construido por Mariano Benlliure, a quien le unía gran amistad ${ }^{54}$ y quien también visitó Piedra en el verano de 1898, dejando su firma el día 26 de agosto. Benlliure acudió a Piedra acompañado del sobrino del tenor, Valentín Gayarre, a quien el cantante dejó parte de su testamento ${ }^{55}$.

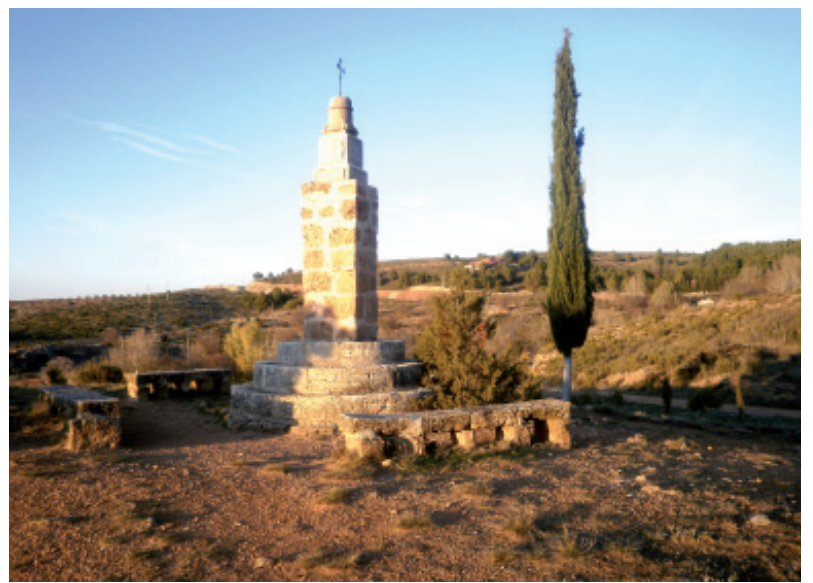

Figura 6. La Cruz de Gayarre al atardecer, Monasterio de Piedra, noviembre 2011. Fot. autora.

53 SARTHOU CARRERES, Carlos: ABC, 17 diciembre 1922, pp. 11-13.

54 http://www.juliangayarre.com/images/mausoleo.pdf [última consulta, marzo 2016].

55 BOSQUED, Pilar: Arte en Piedra: Artes y artistas en los álbumes de firmas del Monasterio de Piedra entre 1861 y 1912. (Texto inédito) 


\subsection{Evaristo Arnús. 2 de julio de 1887}

El banquero Evaristo Arnús mantuvo relación con la familia Muntadas y fue prestamista de Federico. Estuvo también relacionado con la música y el teatro, pues Arnús había adquirido en 1881 los terrenos del teatro Cagé situados en los Campos Elíseos del Paseo de Gracia barcelonés, conocido por Teatro Liric o sala Beethoven.

Un par de años antes, en 1879, y «con el objeto de impulsar la producción de que es susceptible la finca [...], a la vez que proporcionar unas comodidades y amenidad a los concurrentes en la estación del estío a este grandioso sitio», es decir, el Monasterio de Piedra, Federico Muntadas, tomó en Barcelona «a préstamo varias cantidades de importancia», a varias personas, entre las que se encontraba Evaristo Arnús Ferrer ${ }^{56}$ y se comprometió a devolver las cantidades en un plazo de cinco años. En 1901 Federico continuaba teniendo una hipoteca a favor de Arnús, y otros, que sería finalmente cancelada. Lo cierto es que Arnús falleció antes, en diciembre de 1890.

Sea como fuera, y en cualquier caso, parece que Arnús vino acompañado, «en compañía de las familias Göbel, Montalvo y Garí», algunos de cuyos miembros firmaron a continuación.

\subsection{Carlos Fernández Shaw, 11 de julio de 1890}

El fecundo libretista, amigo de Federico, y estrecho colaborador con Chapí, escribió refiriéndose a la Gruta Iris y Dante:

En la gruta del Iris

A mi respetable y muy querido amigo D. J. Federico Muntadas.

Muchos ya lo dijeron: por el autor

Sublime de la gruta

Parece, a cada instante,

Que van a resurgir, según la ruta

Del poema inmortal, Virgilio y Dante

¡Ah! Si el ilustre vate florentino [sigue...]

Nessun maggior dolore ${ }^{57}$, quizá, ¡oh Dante!

que ver tanta beldad ¡sólo un instante!

¡y al instante rodar en el abismo!

Carlos Fdez Shaw [firma]

Monasterio de Piedra 11.7.90

56 A Arnús por la cantidad de 35.000 pesetas.

57 Subrayado en el original. Lo escribió Dante, "nessun maggior dolore che ricordarse del tempo felice nella miseria...". Se canta en el acto 3 del Otelo de Rossini.
Al día siguiente, 12 de julio de 1890, volvió a firmar, esta vez en compañía de su mujer:

Para las maravillas de este paraíso toda nuestra admiración; para los amabilísimos dueños toda nuestra gratitud.

Cecilia Iturralde de Fernández Shaw [firma]

Carlos Fdez Shaw [firma y fecha]

Testimonio de la amistad que unía a Fernández Shaw con Muntadas es la presencia de su mujer Cecilia Iturralde, la cual firmó también en agosto de 1892 junto a otras señoras, entre ellas la mujer de Federico, $\mathbf{M}^{\mathrm{a}}$ del Carmen Muntadas de Muntadas, «después de un suculento almuerzo servido al pié de la cascada Trinidad» mientras que componían rimas consonantes para un soneto que Eduardo Ozores copió en el álbum.

\subsection{Mariano Vázquez, 28 de julio de 1892; 12 de octubre de 1892}

El compositor granadino Mariano Vázquez Gómez, maestro de la Capilla Real y quien destacó en la interpretación del piano, fue miembro de la Real Academia de Bellas Artes de San Fernando, nombrado académico de número para la sección de Música en $1873^{58}$. Recibió otras muchas distinciones. Fue también director de orquesta y un gran conocedor de la obra de Wagner ${ }^{59}$.

El 28 de julio de 1892 dejó un pentagrama en el álbum, donde escribió Las cascadas, sin duda con la música que le inspiraron las soberbias y variadas caídas de agua de Piedra, firmando a continuación.

Mariano Vázquez regresó ese mismo año a Piedra, firmando de nuevo en el álbum el 10 de octubre de 1892, y en la misma página que lo hicieron Isabel de Borbón, la condesa de Superunda, la marquesa de Nájera, Rafael Breñosa y Alonso Coello ${ }^{60}$.

Curiosamente, volvió a firmar el 12 de octubre de 1892, anotando que lo hacía «de vuelta de la calaverada (Alhama! Calatayud!! Zaragoza!!!) [...] a las 3 y 1/2 de la madrugada».

Vázquez, compañero en la Academia, entre otros, de Barbieri y Arrieta, de quienes se consideraba amigo así como de Sarasate, murió dos años más tarde, en 1894.

58 realacademiabellasartessanfernando.com/assets/docs/academicos/relacion_general_de academicos.pdf

[última consulta, marzo 2016].

59 VÁZQUEZ (1884): VIII.

60 BOSQUED, Pilar: Viajes de la Infanta Isabel por Aragón en 1892 y 1912. (Texto inédito). Estuvo en Piedra del 7 al 10 de octubre de 1892 . 


\subsection{Otto Gompertz; H. Gompertz van Dulken; Elisabeth Vinck [?]. 31 de mayo; 1 y 3 de junio de 1895}

Parientes y/o amigos de origen holandés, relacionados con la rama familiar de los Muntadas afincada en Mála$\mathrm{ga}^{61}$, Otto Gompertz, de Rotterdam, y Helena Gompertz van Dulken dejaron escrito después de poner el año, subrayado, una larga reflexión y un cariñoso agradecimiento en rima. Puede leerse a continuación «La Truite Melodie de Schübert», un pentagrama, la firma y unas palabras escritas en holandés, después traducidas, de una tal Elisabeth Vinck [?]. (Fig.7).

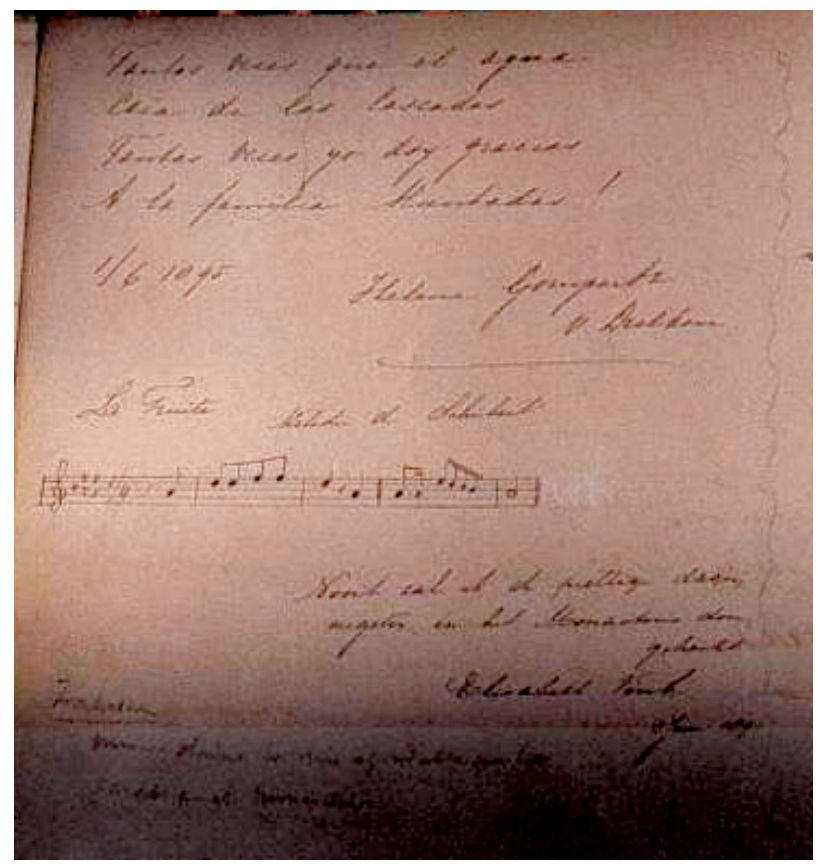

Figura 7. Página con el pentagrama "La Truite. Melodie de Schübert”. Imagen cortesía propiedad. Foto autora.
Se trata del Quinteto para piano en La mayor de la melodía de Franz Schubert Die forelle, la trucha, compuesta en 1819 con texto de Christian F. Schubart. Se desarrolla según una escena en la que alguien observaba un arroyo soleado y transparente donde nadaba alegremente una trucha hasta que fue pescada por un pescador, truncando la felicidad de ambos dos, trucha y observador.

La alusión a la melodía La trucha de Schubert justifica la elección, ya que en el Monasterio de Piedra existe una Piscifactoría con varios estanques, lagos y arroyos, donde se pueden observar a las truchas nadando y saltando fuera del agua en alegre movimiento, truchas que también se encuentran en el río Piedra ${ }^{62}$.

\subsection{Ruperto Chapí, 5 de agosto de 1898; 25 de marzo de 1899}

Muy bien se lo debió pasar el compositor alicantino Ruperto Chapí Lorente en Piedra, como testimonian sus palabras escritas en dos de las páginas del segundo álbum que le dedicó a su amigo Federico Muntadas, afirmando:

Más atrevido que el ilustre Barbieri, yo afronto, ¡oh mi simpático Dn. Federico, la composición de un "Poema Sinfónico" que se titulará "Piedra" y que sería resumen y compendio de mis impresiones en la visita á esta maravillosa "Residencia".

Ahí dejo á V. apuntados los primeros compases de la partitura, que empezando por traer al ánimo el recuerdo del agreste árido y monótono acceso al Monasterio, evocará después, con misteriosos acordes, con cánticos más mas (sic) adivinados que percibidos, la impresión de austeridad, el temeroso aspecto de estos claustros en medio de la pavorosa obscuridad...

Muy luego, se representa la alegre luz de la mañana...la sorpresa....; ; todos los encantos!....

Y por último, si la obra se aplaude, la satis-

facción de dedicar á V., Señor Muntadas, amigo de tantos qe. lo son y que lo fueron míos, unas cuantas páginas de un músico español, cuyas obras, ¡ay!, no durarán lo que estas venerables piedras por las que V. tanto y tan justo entusiasmo siente.

Y ahí van esas notas

62 BOSQUED, Pilar: La piscifactoría del Monasterio de Piedra. Texto inédito.
61 Ramón Muntadas Muntadas, hijo menor de Federico, se casó en Málaga con Elvira Nagel Disdier, cuya hija Elvira Muntadas Nagel se casó con Enrique van Dulken Nagel. Gerardo van Dulken Harts llegó a Málaga desde Rotterdam hacia 1880, casándose con Julia Nagel Disdier, hermana de Elvira. (La Opinión de Málaga, 27 enero 2008 y http://gw.geneanet.org/flofer28?lang=es\&m=S\&n=van+dulken\&p=en rique [última consulta marzo 2016]. Ramón Muntadas y Enrique van Dulken formaron parte de la Primera Junta directiva del club Rotario en Málaga. MATEO AVILÉS (2008): 61, 70-71, 78-79, 83, 86-87, 98, 188, 191, 196,199-200. 
A continuación, el genial compositor incluyó la partitura titulada:

\section{-Piedra- \\ Poema sinfónico \\ (Fragmento)}

Y, seguidamente, escribió la partitura musical, $A l l^{\circ}$ $\operatorname{modt} t^{\circ}$, con las notas, compuestas según el mismo anotó, para Trompas en fa, Timbales, Violoncellos y Contrabajos; Trompas, Timbales. Violines $1^{\circ}$ s, Violcs. y Contr.; Flautas, Oboes, Clarinetes, Fagotes, Trompas, Timbales, Viols $1^{\circ} \mathrm{s}$, Violoncs, Contra.

Finalmente, puso para dejar constancia su firma, el lugar y la fecha: «Ruperto Chapí [firma] Monasterio de Piedra 5-8-98». (Fig. 8).

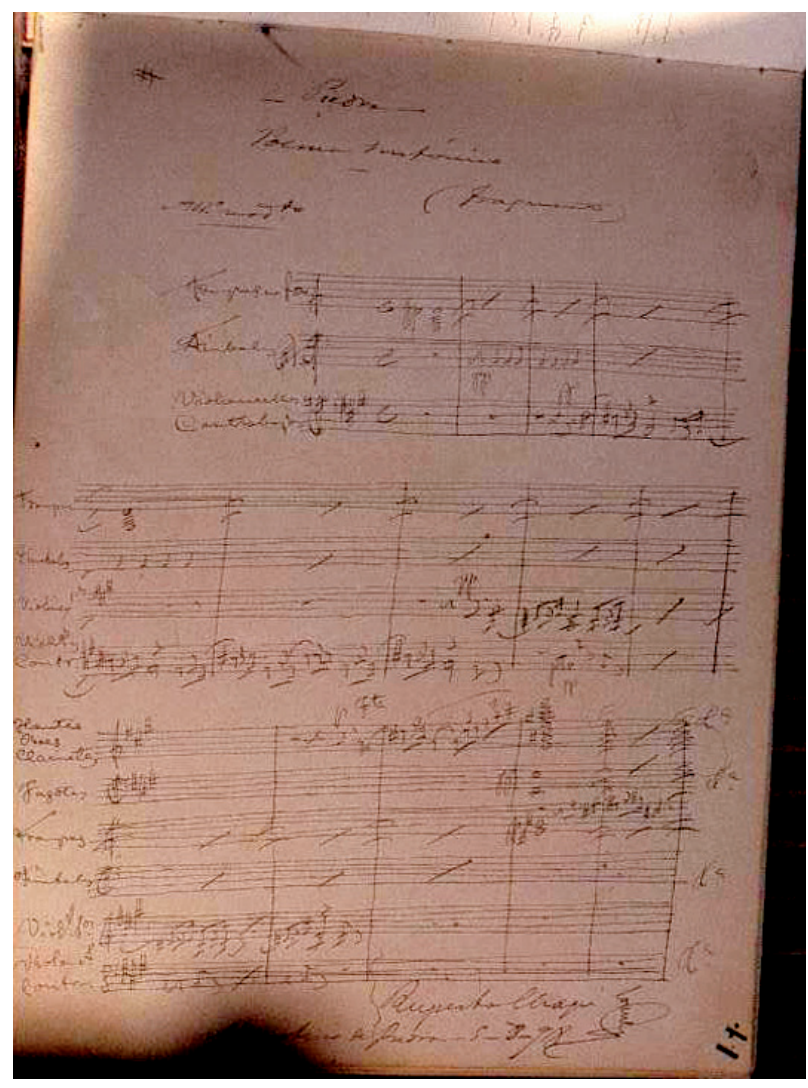

Figura 8. Página de Ruperto Chapí en el álbum de firmas del Monasterio de Piedra. Imagen cortesía propiedad. Fot. autora.

Respecto a la estancia de Chapí en Piedra, Luis Iberni observaba que en una carta dirigida por Chapí a Esperan- za y Sola el 16 de julio de 1898, el maestro escribió que «yo estoy aquí trabajando de firme. Me cunde mucho. Estoy muy contento $[\ldots] »$, mientras que afirmó que «Chapí planeó Curro Vargas muy cerca de Calatayud, en el Monasterio de Piedra». Como se sabe, Curro Vargas es un drama lírico con música de Chapí y texto de Joaquín Dicenta y Antonio Paso que se estrenó en Madrid en ese mismo año de 1898.

Añadía este mismo autor, Iberni, que a Chapí y a Dicenta «les unía su vinculación con la misma tierra (aunque nacido [Dicenta] en Calatayud, la familia provenía de Alicante) o sus vicisitudes al llegar a Madrid», apuntando que no se podía «olvidar la extraordinaria relación que mantuvo Chapí con Dicenta, uno de los autores dramáticos más importantes del momento» ${ }^{63}$.

Chapí escribió a Fernández Shaw ${ }^{64}$ el 21 de julio desde Piedra, señalando que estaba trabajando en el final segundo de Curro Vargas, «que estará compuesto en 5 ó 6 días», puntualizó, añadiendo que el Monasterio de Piedra era «delicioso para trabajar», y definiendo a las antiguas celdas monacales que Muntadas había restaurado para habitaciones como «celditas que no tienen precio» ${ }^{65}$.

Ruperto Chapí sintió que el monasterio de Piedra era un lugar de delicias, valorando la percepción del paisaje que se percibe desde las antiguas celdas convertidas en habitaciones con terraza, a las que definió como estupendas, desde las que se disfruta del sonido de las cascadas y del canto de los pájaros.

Uno año después, Chapí volvió a firmar, acompañada su firma de quienes se autoproclamaron como autores de Curro Vargas, esto es, Manuel Paso, Joaquín Dicenta, autor teatral, poeta y periodista nacido en la cercana Calatayud y del que ya hemos hablado, y Tomás Trevijano, si bien este último añadió que lo hacía como amigo de Curro Vargas:

Los autores de Curro Vargas ${ }^{66}$ saludan con admiración por su grandeza con gratitud por haberle prestado sus bellezas todas para una(i) al monasterio de Piedra Marzo 25/99

Manuel Paso [firma]

63 GRACIA IBERNI (2009): 206, 283, 291 y 299.

64 También a Fernández Shaw le pareció el lugar estupendo, donde, como ya hemos visto, fue acompañado de su mujer, Cecilia Iturralde, en julio de 1890 .

65 Ver al respecto: Fernández Shaw, Carlos. Archivo de Carlos Fernández Shaw. Madrid: Fundación Juan March, 2011[consulta: 24 enero 2012] Disponible en Web: http://www.march.es/bibliotecas/legados/cfs/; GRACIA IBERNI (2009): 264.

66 Subrayado en el original. 
Ruperto Chapí [firma]

Joaquín Dicenta [firma]

Como amigo de Curro Vargas

Tomas Trevijano [firma]

Chapí fue elegido académico de número para la sección de Música de la Real Academia de Bellas Artes de San Fernando en $1889^{67}$.

\subsection{Vicente Zurrón, 16 de mayo de 1902}

El compositor y pianista aragonés Vicente Zurrón ${ }^{68}$, y amigo de Chapí, con cuyo hijo también colaboró, dejó el testimonio en el álbum de su paso por Piedra. De manera escueta y enérgica firmó con su nombre: Vicente Zurrón y fecha, sin añadir nada más.

\subsection{José López Salaberry, 7 de septiembre de 1903}

El distinguido arquitecto madrileño José López Salaberry, arquitecto municipal y coautor de la Gran Vía madrileña entre otras muchas obras, viajó en compañía de Ricardo López Salaberry, quien dejó una extensa impresión sobre el lugar, firmando los dos a continuación.

Tal y como se puede leer en la necrológica del arquitecto, José «tenía afición muy señalada a la música, y se dedicó con fervor a su estudio, llegando a producir algunas composiciones, sin propósito de publicidad ni de lucro y sin más finalidad que su propio deleite» ${ }^{69}$.

Un tal [i]Pepón[?] firmó al final de un pentagrama que insertó a continuación de las firmas, un precioso pentagrama musical, bellísima y pulcramente ejecutado, dejando el autor constancia de su dominio del dibujo y de su afición musical.

Tiempo de Jota

Ya perdí de vista el Va.....do, ya estoy vien.....do el Monas....te.....rio Ya perdí de vista el Va...... do Guardaré como reli......quia la impresión que me causa........ron Ya estoy vien.........do el Monasterio, ya per. dí de vis.........ta el Va.......do.

[¿]Pepón[?] (Fig.9)

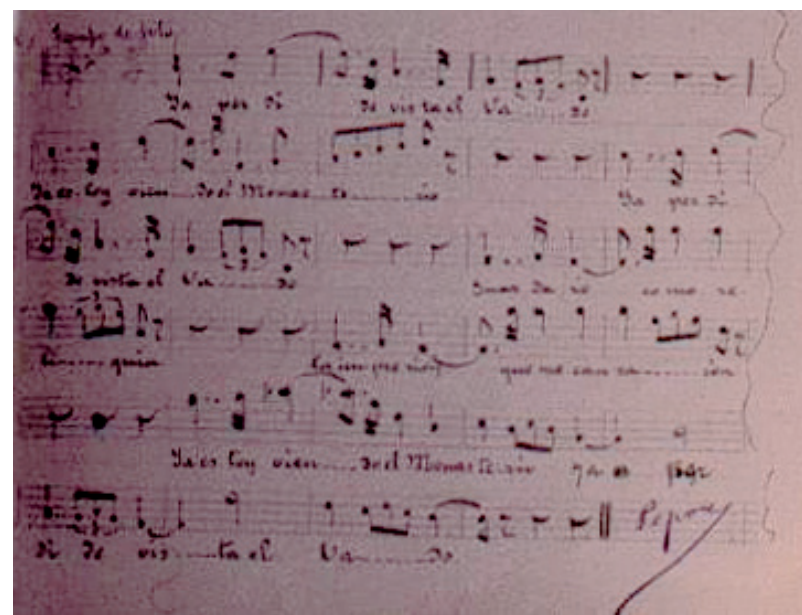

Figura 9. Jota en el álbum de firmas del Monasterio de Piedra. Imagen cortesía propiedad. Fot. autora.

La letra alude a la espectacular cascada del Vado, definida en muchas ocasiones y tal y como recogió su propietario como «la sinfonía de todas las cascadas» ${ }^{70}$. La cascada estuvo situada a unos tres kilómetros aguas arriba del Monasterio de Piedra, en Lugar Nuevo, una preciosa finca que también compró Muntadas. Según afirmaron en su publicación los primos Muntadas, nietos de Federico, esta cascada desapareció «como consecuencia del salto hidroeléctrico» que se realizó en el lugar ${ }^{71}$.

Actualmente, a Lugar Nuevo se puede llegar a pie, en delicioso y pintoresco paseo junto al río Piedra, o por vehículo por carretera, pero siempre entre un paisaje singular, paisaje y recorrido que formaba parte del itinerario y visita turística que se realizaba mientras que Federico Muntadas vivió y hasta que desaparecieron las cascadas del Vado, de la Niña y el torrente de los Peñascos. Es muy probable que regresando de la excursión al Vado, que en los primeros años se solía hacer en burra o mulo, cantaran los excursionistas esta jota, que luego anotó su autor con primor en el álbum.

José fue elegido en 1901 académico de número para la sección de Arquitectura de la Real Academia de Bellas Artes de San Fernando ${ }^{72}$.

70 JORNET [1871]: 52-56.

71 MUNTADAS NAGEL; MUNTADAS-PRIM SALVADÓ (1970): 74

72 realacademiabellasartessanfernando.com/assets/docs/academicos/relacion_general_de_academicos.pdf

[última consulta, marzo 2016]. 


\subsection{L'Associació Wagneriana de Barcelona. [junio] de 1912}

L'Associació Wagneriana de Barcelona visitó en 1912 el Monasterio de Piedra, año en el que dejó el testimonio de su visita ocupando dos páginas, en las que no se consignó la fecha pero que aparecen en el álbum entre las de abril y julio de 1912 .

Estas fechas concuerdan con lo expresado por Paloma Ortiz de Urbina en su artículo sobre el Bayreuth español, donde da a conocer la correspondencia entre las asociaciones wagnerianas de Madrid y Barcelona, y en donde se refleja que la expedición quedó concertada para los días 8 y 9 de junio, pero que la de Madrid no pudo acudir al monasterio de Piedra, pero que sí que lo hizo la de Barcelona, expedición formada por Joaquín Pena, el redactor crítico de arte y de $L a$ Publicidad Jori ${ }^{73}$.

En efecto, en una de las páginas del álbum se incluyó el dibujo del sello de la Asociación de Barcelona, seguido de un fragmento de la partitura Parsifal copiado por el afamado músico Joan Lamote de Grignon, así como un dibujo realizado y firmado por Oleguer Junyent, quien representó una cascada con un pez, (¿una trucha?) y un grupo de personas admirando el escenario, y las palabras traducidas al catalán por el crítico musical Joaquim Pena.

Este hecho quedó reseñado por los primos Muntadas, quienes consignaron en su publicación los «propósitos wagnerianos» que proyectaron los Wagnerianos de Bayreuth entre 1912 y 1913 «por montar en determinados parajes del Parque de Piedra y a modo de teatro naturaleza, alguna de las obras del famoso compositor, concretamente [...] la Walkiria o Sigfrido y su obra cumbre, el Parsifal», pero que la Primera Guerra Mundial, que comenzó en 1914, dio al traste con el proyecto ${ }^{74}$.

Afirmaron igualmente que «el famoso maestro J. Lamothe de Griñón, Presidente a la sazón de la "Assoçiaçió Wagneriana de Barcelona", sin mencionar el mes pero ocurrido en el verano de 1912», es decir, poco antes de que falleciera Federico Muntadas, «pone sobre el pentagrama las notas de un pasaje del Parsifal, y un acompañante, Joaquín Pena, complementa la música resultante con estos versos "per la traducció" $[\ldots] »^{75}$.

73 ORTIZ DE URBINA (2014): 55-64. http://revistes.ub.edu/ index.php/materia/article/view/11678/14511 [última consulta: enero 2016]

74 MUNTADAS NAGEL; MUNTADAS-PRIM SALVADÓ (1970): 21-22.

75 MUNTADAS NAGEL; MUNTADAS-PRIM SALVADÓ (1970): 18
Así, puede verse en el álbum:

R. Wagner.- $\underline{\text { Parcival }}^{76}$

per la copia

J. Lamote de Grignon [firma]",

[a la izquierda de la página, dibujo]

O. Junyent [firma]

"Oh, preneu el meu Cos

oh, preneu ma Sang

de mon Amor ofrena

per la traducció

Joaquim Pena [firma] (Fig. 10)

[...continúa la dedicatoria escrita]

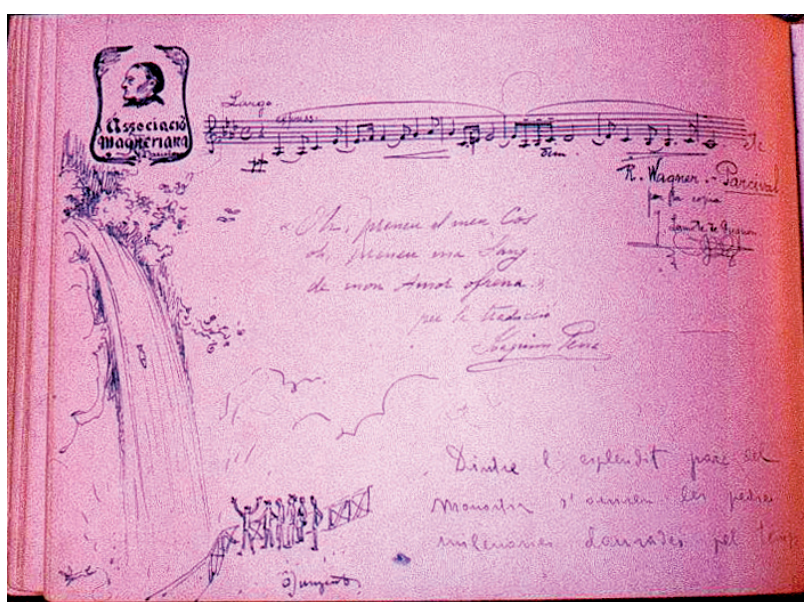

Figura 10. Una de las páginas que la Associació Wagneriana dejó en el álbum de firmas. Imagen cortesía propiedad. Fot. autora.

Los primos Muntadas aseguraron que «Romá Jové, que formaba parte de la expedición, inicia y termina sus inspirados pensamientos con estas palabras:-“Dintre del esplendid Parc del Monastir s'uniren las pedras millenaries dauradas per el temps i per la llum. La Consagraçió del Grial sols se pot comprendre dintre d'un lloc ahont se sent per lo remor de las cascades la veu de Deu"» ${ }^{77}$.

El caso es que Manuel Muntadas Rovira, primo de Federico e hijo de su tío José Antonio con quien Federico mantuvo estrecha amistad, publicó en 1910 acerca del tema wagneriano, titulando dos obras suyas como Probable origen català de les llegendes del Sant Graal y Balades wag-

76 Subrayado en el original.

77 MUNTADAS NAGEL; MUNTADAS-PRIM SALVADÓ (1970): 19 . 
nerianes. Resultaría posible que Manuel Muntadas tuviera mucho que ver en el deseo de las asociaciones wagnerianas, sobre todo la de Barcelona, de llevar a cabo en el monasterio de Piedra estas representaciones wagnerianas.

De igual modo, tal y como acabamos de esgrimir, existen algunos indicios por los que sería también probable que las asociaciones wagnerianas hubieran retomado la idea de representar algunas obras de Wagner según se había realizado en otros intentos anteriores que no llegaron a término por diferentes motivos, todavía sin esclarecer.

Por su parte, la familia Muntadas explicó el asunto wagneriano de manera algo confusa. Así, los primos Muntadas aseguraban que «en el transcurso de 1912, 1913, cuando de hecho administraba la propiedad $\mathrm{D}^{\mathrm{a}}$ Pilar $^{78}$ [hija de Federico], los wagnerianos de Bayreuth, se interesaron por montar en determinados parajes del Parque de Piedra y a modo de teatro naturaleza, alguna de las obras del famoso compositor, concretamente una de su tetralogía -se barajaban la Walkiria o Sigfrido- y su obra cumbre, el Parsifal.» Explicaron que «vino una comisión a Piedra en 1913, quedando plenamente satisfecha de sus especiales circunstancias de belleza del paisaje, grandiosidad del escenario, y, al parecer perfectas condiciones acústicas». Aseguraron que la comisión mostró su preferencia «por el Lago del Espejo y Peña del Diablo [...] arboledas y prados del Vergel [...] y el Torrente de los Mirlos [...]» ${ }^{79}$.

Wagner ideó para Die Walküre, Siegfried y Parsifal escenarios diversos, que se podían encontrar en Piedra. Parsifal necesitaba entre otros decorados, un bosque, un castillo, un lago, un jardín de flores, una cabaña de ermitaño, un cisne y una paloma blanca. Algunos de estos elementos estaban en la zona del Lago del Espejo.

La Walkiria precisaba un árbol o fresno, una montaña rocosa y alguna roca, mientras que Sigfrido una cueva, un bosque, una roca y un sendero. Por su parte, en El Oro del Rin se hablaba del puente del arco iris. En la zona junto al río Piedra estaban los fresnos, y las cascadas de los Fresnos Altos y Fresnos Bajos, escarpadas rocas por donde se precipita el río, la cueva o gruta del Artista, de la Bacante y de la Pantera, el bosque e incluso un puente junto a la Cascada Iris.

Tal y como indicaba Jordi Mota, la Asociación Wagneriana de Madrid se fundó en 1911, duró tan solo tres años,

78 Pilar Muntadas fundó el Magisterio Católico, que tuvo su casa matriz en el Monasterio de Piedra. Algunas de las obras de Pilar estaban relacionadas con la música, como Cantos religiosos, Gimnasia rítmica, Cantos pedagógicos y LX Coplas para las alumnas del Magisterio Católico.

79 MUNTADAS NAGEL; MUNTADAS-PRIM SALVADÓ (1970): 21 . hasta 1914, «desarrolló una actividad arrolladora», y que en la Memoria se podía leer que «el 26 de febrero se recibió una comunicación de la Asociación Wagneriana de Barcelona, exponiendo el proyecto de conmemorar el Centenario del Maestro con una representación del "Parsifal" en el Monasterio de Piedra, para que la primera audición en España de su último drama tuviera se hiciera en unas condiciones tales que constituyesen el mayor y más digno homenaje que las dos Asociaciones hermanas podían tributar a la memoria del gran poeta-músico [...pero que] el proyecto no tuvo lugar» ${ }^{80}$.

En su tesis doctoral Paloma Ortiz de Urbina dio a conocer la correspondencia entre las Asociaciones Wagnerianas de Madrid y Barcelona ${ }^{81}$, mientras que en 2014 concluía que «el sueño del Proyecto de Piedra, concebido como un Bayreuth ibérico, como un lugar de peregrinaje para los wagnerianos nacionales pero con decidida proyección internacional $[\ldots]$ » no fue posible, destacando los problemas de índole económica ${ }^{82}$.

También aborda el tema María Infiesta quien en su artículo sobre Francisco Viñals i Dordal refleja que el ambicioso proyecto contemplaba igualmente la construcción de «un tranvía eléctrico [...]» ${ }^{83}$, desde la cercana Alhama de Aragón, donde se encuentra la estación ferroviaria más cercana y los establecimientos hoteleros que podían completar al de Piedra, como hemos visto proyectos similares a los otros de años anteriores.

Pero a pesar de las condiciones idóneas que parecían darse en Piedra, lo cierto es que los primos Muntadas aseguraron que «la primera gran conflagración europea» abortó esa idea y que «la correspondencia entre los directivos alemanes y la propiedad de la finca» había desaparecido, apuntado al hecho probable de que se perdieran cuando Pilar Muntadas se trasladó a Zaragoza ${ }^{84}$.

Por su parte, Ortiz de Urbina aclara algo más el asunto al asegurar que en ese año de 1914 terminaba la fecha propuesta por las asociaciones wagnerianas para su proyecto, ya que el «plazo de protección iba a expirar en toda Europa el 1 de enero de 1914» para el Parsifal de Wagner ${ }^{85}$.

80 MOTA, Jordi: La efímera, pero fructífera Asociación Wagneriana de Madrid. Wagneriana castellana ${ }^{\circ}$ 32, año 1999. En: http:// www.associaciowagneriana.com/pdfarticles/wagnerianademadrid.pdf. [última consulta: enero 2016]

81 ORTIZ DE URBINA Y SOLANO (2004): 315-330. (Ver: http://eprints.ucm.es/tesis/ghi/ucm-t26883.pdf.) [última consulta noviembre 2015].

82 ORTIZ DE URBINA Y SOLANO (2014): 64.

83 INFIESTA (2013). En: http://associaciowagneriana.com/ pdfarticles/876187360338.pdf [última consulta: enero 2016]

84 MUNTADAS NAGEL; MUNTADAS-PRIM SALVADÓ (1970): 21-22.

85 ORTIZ DE URBINA (2014):1 y 65. 
En cualquier caso, todo parece indicar que además de los problemas de financiación ${ }^{86}$, además de que se produjera el fin de la primera etapa de la asociación wagneriana madrileña, además de que expirara el plazo de protección mencionado y además de las dificultades e inconvenientes derivados de la primera guerra mundial, se añadió el nuevo problema de la muerte del propietario en octubre de 1912 y el engorroso y muy complicado asunto de su herencia.

Por otra parte, a pesar de que las actuaciones wagnerianas no se llevaron a cabo, sí que se tomaron en serio alguna de las ideas entonces esbozadas, ya que la propiedad tuvo «el propósito de alumbrar discretamente los accesos al Vergel, a efectos de poder contemplar las Cascadas en las noches de plenilunio [...]» ${ }^{87}$, idea que habían esbozado las asociaciones wagnerianas, quienes pensaron en utilizar el Vergel «en noches de plenilunio para enmarcar los pasos ya de Sigfrido, ya de Parsifal» ${ }^{88}$.

\section{LA MÚSICA DEL RÍO PIEDRA, EL SILENCIO Y EL ECO EN EL MONASTERIO DE PIEDRA}

Existe otra «música natural», o sonido, en el parque, vergel y jardín del Monasterio de Piedra que es la que proporciona el agua del río Piedra al precipitarse por sus muchas cascadas o por su peculiar discurrir entre escalones naturales de piedras. Como hemos visto, uno de los primeros en dejar constancia de esa música fue el propio Muntadas.

A esta melodía acuática hay que añadir otra procedente del mundo animal: el concierto espontáneo, natural y constante del canto de las aves que se localizan en el cenobio y en el lugar, donde destacan los trinos de ruiseñores, gorriones, mirlos y otros pájaros.

Incluyo igualmente el silencio y el eco, muy presentes en determinados lugares, sobre todo de su arquitectura, a ciertas horas del día y, sobre todo, durante la noche.

\subsection{EI Torrente de los Mirlos}

El denominado Torrente de los Mirlos es un rincón singular donde el agua discurre rápida y alegremente, al que Federico Muntadas describió señalando que el torrente se lanzaba «atropelladamente sobre una pendiente de roca» ${ }^{89}$. Allí, los pájaros sobrevuelan alegremente el espacio y se

86 Se calculó que se necesitaba un millón de pesetas. (1970): 68.

87 MUNTADAS NAGEL; MUNTADAS-PRIM SALVADÓ (1970): 21

88 MUNTADAS NAGEL; MUNTADAS-PRIM SALVADÓ 89 JORNET [1871]: 38 y 39. acercan al agua a beber, inundando el aire con sus trinos, componiendo una extraña atmósfera de contrastes entre el rugir del agua de las cascadas y el río y la suavidad del canto de las aves. Como se sabe, los mirlos son aves canoras que emiten un canto bellísimo, considerado por la mayoría de los músicos como el más bello y afinado entre los pájaros.

El torrente tiene un impresionante telón de fondo: las cascadas Trinidad y Caprichosa, caídas de menor caudal, como la Solitaria y otra innominada, o la bellísima Baño de Diana, donde existe la posibilidad de bañarse en su poza y también en la de la Caprichosa. Las grutas de la Bacante, de la Pantera y del Artista y el propio río Piedra, que podría ser interpretado como alegoría al Rin, complementan el singular rincón.

Según relacionaron los primos Muntadas, los wagnerianos pensaron que el Torrente de los mirlos era el lugar adecuado para representar «la muerte del héroe germano, atravesado por la lanza de Hagen, mientras desalteraba su ardiente sed al final de la victoriosa y velocísima carrera ${ }^{90}$.

La escena de la muerte de Sigfrido forma parte de la ópera El Ocaso de los dioses, Götterdammerung, cuyo decorado precisaba rocas, troncos de árbol, riberas, un río en donde pudieran bañarse las ninfas u ondinas, aves del bosque y un bosque.

\subsection{EI Valle del Silencio}

El silencio se deja sentir de manera extraordinaria en la zona del Lago del Espejo, antes llamado Lago de la Peña del Diablo $^{91}$, al pie de la Peña del Diablo que le daba su antiguo nombre. Está situado junto a la piscifactoría, un lugar que quedó igualmente definido por Ozores como el Valle del Silencio ${ }^{92}$, que es el nombre que he escogido en este apartado del artículo.

El silencio que se disfruta en ese paraje contrasta con el bullicio acuático, a veces estruendoso, que acompaña a lo largo del recorrido entre cascadas, arroyos y caídas de agua, recorrido que ha debido caminar hasta llegar allí, es decir, hasta llegar al silencio.

El lago, en realidad un estanque grande que contiene las aguas retenidas de varios surgideros y manantiales, está rodeado por altas peñas de color gris anaranjado. Los acantilados, la Gruta del Desertor y la Peña del Diablo forman un escenario paisajista verdaderamente sublime, con el lago de

90 MUNTADAS NAGEL; MUNTADAS-PRIM SALVADÓ (1970): 21

91 Según la hoja impresa [s. f.] de una "Guía del visitante" que se entregaba junto con la entrada, el nombre de Lago del Espejo estuvo "aconsejado por el ilustre D. Francisco Pi y Margall".

92 OZORES (1892): 13 y 18. 
aguas tranquilas y efectos de espejo a los pies de las paredes rocosas, donde se reflejan. Se trata de un sorprendente, cálido y apacible rincón donde se escuchan en plenitud los sonidos de la naturaleza, especialmente los cantos y trinos de las aves que alternan sucesivamente con las pausas o silencios.

Los primos Muntadas afirmaron que los wagnerianos pensaron que «sobre la Peña del Diablo, se proyectó el despertar del sueño de Brunhilda, [y que] los "cañones" policromáticos del Lago del Espejo, se consideraron insuperables para los dos marchas de Parsifal al castillo sagrado de Monsalvate $($ sic $) »^{93}$.

Desde el Lago del Espejo se puede ver la Torre del Homenaje, tanto reflejada en la superficie del agua del lago cuando el agua está en reposo y quieta, hecho que se da con frecuencia, como recortada contra el cielo y en lo alto.

\subsection{El Eco}

En muchos lugares del monasterio de Piedra se produce el eco. Es el caso que se da en los extensos pasillos del hotel o en ciertos lugares de su arquitectura, como en los claustros. Por desgracia, ha desaparecido el probable eco que se debía producir en la iglesia, que se encuentra en ruinas y sin tejados ni cubiertas.

También se escucha en algunos recodos del Lago del Espejo, un lugar de excepcional y especialísima acústica.

\section{LA MÚSICA QUE SINTIERON Y CANTARON LAS PERSONAS MENCIONADAS EN EL TEXTO ANTE LA CONTEMPLACIÓN DEL PARQUE, VERGEL, JARDÍN Y EDIFICIOS EN EL MONASTERIO DE PIEDRA}

\author{
En la Cruz de Piedra o Cruz de Gayarre: Spirto gentil \\ de Donizetti. \\ En el acceso y/o en los claustros: Piedra de Chapí. \\ En la piscifactoría: Die forelle de Schubert. \\ Ante las grutas, lagos y cascadas: Sinfonía pastoral de \\ Beethoven. \\ Ante la cascada Caprichosa: Parsifal de Wagner. \\ Junto al Torrente de los Mirlos: El ocaso de los Dioses \\ de Wagner. \\ En el Lago del Espejo: Parsifal de Wagner. \\ Ante Iris: Otelo de Rossini. \\ Bajando de la desaparecida Cascada del Vado: una \\ Jota (creación de autor).
}

93 MUNTADAS NAGEL; MUNTADAS-PRIM SALVADÓ (1970): 21 .

\section{CONCLUSIÓN}

El monasterio de Piedra provoca sentimientos de sublimidad, impregnados de romanticismo y cualidades pintorescas, que en la segunda mitad del siglo XIX y primeros años del siglo XX se manifestaron en las artes y en las letras de forma acusada y continua. Es el caso del arte de la música que se vivió de especial manera en el monasterio de Piedra durante estos años analizados.

La contemplación del paisaje exterior, antaño árido y apenas cubierto de vegetación, la incomodidad del viaje hacia ese recóndito lugar y el contraste de la riqueza de la naturaleza excepcionalmente manifiesta en el vergel, con sus caídas de agua y cascadas y en la zona del Lago del Espejo, favorecían la exaltación de las emociones.

Esto mismo sucedía con la contemplación del paisaje intramuros del cenobio, con las ruinas, los edificios singulares, los patios, las murallas, las huertas, el vergel y los jardines, que complementaban el extraordinario conjunto y proporcionaban decorados escénicos románticos de gran pintoresquismo y sublimidad.

Si Barbieri se sintió empequeñecido ante la solemne gruta Iris y desistió de componer música abrumado por la furia del agua del río Piedra en su caída por delante de esa gruta, Arrieta asimiló el paisaje y la naturaleza de este lugar con Beethoven. Por su parte, Sarasate también se inspiró en el monasterio de Piedra, mientras que el tenor Gayarre quedó tan embriagado por la magnificencia del paisaje que no pudo reprimir el canto, surgido de forma espontánea ante el sublime panorama.

La especial disposición del monasterio, en una hondonada, del vergel, oculto y hundido en su parte más honda y rodeado por escarpadas paredes, y de la zona del Lago del Espejo y Peña del Diablo llevó a sus propietarios y a las asociaciones wagnerianas de Barcelona y de Madrid a pensar en representar en este lugar alguna de las óperas de Wagner, quizá retomando iniciativas anteriores que no se habían llevado a término.

El monasterio de Piedra ofrecía características escenográficas idóneas paras algunas de las obras wagnerianas, para lo cual pensaron construir un anfiteatro, un teatro en la naturaleza, complementado por edificios en ruinas y de carácter medieval que proporcionaban el telón y el decorado perfecto para la música romántica.

Algunos banqueros estrechamente vinculados a la música y patrocinadores de actividades musicales, prestaron a Federico Muntadas diversas cantidades. Existen indicios de que algunos miembros de la familia Muntadas mantuvieron contactos con el mundo teatral, relacionado con la música, y sería posible que algunas de las escenas jardineras y paisajistas hubieran podido tener su origen, evolución, construcción 
o transformación en el deseo de adecuar ciertos espacios para disfrutar de la música, del teatro y la poesía en determinados momentos y zonas.

El parque, vergel y jardín del monasterio de Piedra proporcionó desde mediados del siglo XIX, y sigue proporcionando, decorados perfectos para inspirar a diversas artes, ya sea la pintura como la literatura, la música y el arte de la jardinería, en la mayoría de los casos complementados y enriquecidos entre sí.

\section{BIBLIOGRAFÍA}

Balaguer, Víctor, Guía del viajero en Piedra. Barcelona, Librería de Juan y Antonio Bastinos, 1882.

Bosqued, Pilar, "Las aguas mineromedicinales del Monasterio de Piedra", Anales de la Real Academia de Medicina de Zaragoza. Conferencias y Comunicaciones. Zaragoza, 31 de diciembre de 2010, vol. XCVI (2010), 215-244.

Bosqued, Pilar, Historia de las aguas mineromedicinales del Monasterio de Piedra. Zaragoza, Institución «Fernando el Católico», 2013.

Bosqued, Pilar, "Carlos de Haes en Aragón y en el Monasterio de Piedra. Estudio del paisaje de antaño y actual", Academia. Boletín de la Real Academia de Bellas Artes de San Fernando, 114-115 (2012-2013), 119-139.

Bosqued, Pilar, "La piscifactoría de la Granja de San Ildefonso y su relación en la segunda mitad del siglo XIX con las de Huningue y el Monasterio de Piedra", Reales Sitios, L/195 (primer trimestre, 2013), 65-80.

Casares Rodicio, Emilio (dir.), Diccionario de la Música Española e Hispanoamericana. 10 vols. Madrid, SGAE, 1999-2002.

Casares Rodicio, Emilio (dir.), Diccionario de la Zarzuela. España e Hispanoamérica. Volumen I y II, $2^{\mathrm{a}}$ ed., Madrid, ICCMU, 2006.

Cavia Naya, Victoria, "Un músico del siglo XIX y su proyección desde la catedral de Valladolid: Hilario Prádanos", en Cuadernos de Música Iberoamericana, 7 (1999), 199-214.

Dicenta Benedicto, Joaquín, De Piedra a Piedra. Cartagena (Murcia), Artes Gráficas de Levante, 1905. Reed. Con estudio, compilación y notas de Jesús Andrés Zueco. Calatayud, López Alcoitia, 1994.

Gracia Iberni, Luis Miguel, Ruperto Chapí, Madrid, IсCмU, 2009.

Heredia, Rafael, Álbum del Monasterio de Piedra, Madrid, Hernando y Compañía, 1900.
Infiesta, María: "Francisco Viñas i Dordal. Mucho más que un tenor wagneriano", Associació Wagneriana. Barcelona. Revista wagneriana en castellano, 103 (2013).

Jornet, Leandro [Muntadas, Federico], El Monasterio de Piedra. Su historia. Valles, cascadas y grutas. Leyendas monásticas. Madrid, Rivadeneyra, [1871].

López Morell, Miguel A., La Casa Rothschild en España (1812-1941). Madrid, Marcial Pons, 2005.

Mateo Avilés, Elías de, Los rotarios en Málaga (1927-1936) Un espacio de tolerancia, progreso y solidaridad al filo de la Guerra Civil, Málaga, Fundación Málaga, 2008.

Muntadas, Juan Federico, Vida y hechos de Gil Pérez de Marchamalo, 2 tomos, Madrid, M. Rivadeneyra, 1866.

Muntadas Nagel, Elvira y Muntadas-Prim Salvadó, Luis, Recuerdos y hechos sucedidos en el ex Monasterio de Piedra desde que éste pasó a propiedad privada, hacia 1840, Barcelona, s.e., 1970.

Muntadas Rovira, Manuel: Probable origin català de les llegendes del Sant Graal. Barcelona, L'Avenç, 1910.

Muntadas Rovira, Manuel, Balades Wagnerianes, Barcelona, Francesch Puig, 1910.

Ortiz de Urbina y Solano, Paloma: La recepción de Richard Wagner en Madrid (1900-1914). Tesis doctoral. Madrid, Universidad Complutense de Madrid, 2004.

Ortiz de Urbina, Paloma, "Un «Bayreuth español» para 1913: wagnerianos de Madrid y Barcelona en un proyecto común", Matèria [Universitat de Barcelona], 8 (2014), 47-84.

Ozores, Eduardo, Un Verano en Piedra. Impresiones y bocetos, Madrid, editorial?, 1892.

Scholes, Percy A. (dir.), Diccionario Oxford de la Música. Tomo II. Barcelona, Edhasa, 1984.

Sociedad del Gran Teatro del Liceo, Gran Teatro del Liceo. Cincuentenario de su inauguración. Recuerdo de la función dedicada a celebrar este acontecimiento. Barcelona, Imprenta de Jaime Jesús Roviralta, 1897.

Soriano Fuertes, Mariano, Historia de la Música española desde la venida de los Fenicios hasta el año de 1850, Madrid-Barcelona, Martín y Salazar-Narciso Ramírez, 1855.

Vázquez, Mariano, Cartas a un amigo sobre la música en Alemania. Apuntes de viaje, Madrid, Imprenta central a cargo de Víctor Saiz, 1884.

Zabala y Gallardo, M., "Necrología del Ilmo. Sr. D. José López Salaberry", en Arqvitectvra. Revista mensual. Órgano Oficial de la Sociedad Central de Arquitectos [Madrid], número? (julio 1927), 239. 